\title{
Application of ion-engineered Persian Gulf seawater in EOR: effects of different ions on interfacial tension, contact angle, zeta potential, and oil recovery
}

\author{
Amir Hossein Saeedi Dehaghani ${ }^{1}$. Seyed Masoud Ghalamizade Elyaderani ${ }^{1}$
}

Received: 23 July 2020 / Accepted: 20 November 2020 / Published online: 17 January 2021

(c) The Author(s) 2021

\begin{abstract}
In this study, we initially performed interfacial tension (IFT) tests to investigate the potential of using the Persian Gulf seawater (PGSW) as smart water with different concentrations of $\mathrm{NaCl}, \mathrm{KCl}, \mathrm{MgCl}_{2}, \mathrm{CaCl}_{2}$, and $\mathrm{Na}_{2} \mathrm{SO}_{4}$. Next, for each salt, at the concentration where IFT was minimum, we conducted contact angle, zeta potential, and micromodel flooding tests. The results showed that IFT is minimized if $\mathrm{NaCl}$ or $\mathrm{KCl}$ is removed from PGSW; thus, for solutions lacking $\mathrm{NaCl}$ and $\mathrm{KCl}$, the IFT values were obtained at 26.29 and $26.56 \mathrm{mN} / \mathrm{m}$, respectively. Conversely, in the case of divalent ions, minimum IFT occurred when the concentration of $\mathrm{MgCl}_{2}, \mathrm{CaCl}_{2}$, and $\mathrm{Na}_{2} \mathrm{SO}_{4}$ in PGSW increased. Specifically, a threefold rise in the concentration of $\mathrm{Na}_{2} \mathrm{SO}_{4}$ further reduced IFT as compared to optimal concentrations of $\mathrm{MgCl}_{2}$ or $\mathrm{CaCl}_{2}$. It should be mentioned that eliminating $\mathrm{NaCl}$ from PGSW resulted in the lowest IFT value compared to adding or removing other ions. Whereas the removal of $\mathrm{NaCl}$ caused the contact angle to decrease from $91.0^{\circ}$ to $67.8^{\circ}$ relative to PGSW and changed surface wettability to weakly water-wet, eliminating $\mathrm{KCl}$ did not considerably change the contact angle, such that it only led to a nine-degree reduction in this angle relative to PGSW and left wettability in the same neutral-wet condition. At optimal concentrations of $\mathrm{MgCl}_{2}, \mathrm{CaCl}_{2}$, and $\mathrm{Na}_{2} \mathrm{SO}_{4}$, only an increase in $\mathrm{Na}_{2} \mathrm{SO}_{4}$ concentration in PGSW could change wettability from neutral-wet to weakly water-wet. For solutions with optimal concentrations, the removal of $\mathrm{NaCl}$ or $\mathrm{KCl}$ caused the rock surface to have slightly higher negative charges, and increasing the concentration of divalent ions led to a small reduction in the negative charge of the surface. The results of micromodel flooding indicated that NaCl-free PGSW could raise oil recovery by $10.12 \%$ relative to PGSW. Furthermore, when the $\mathrm{Na}_{2} \mathrm{SO}_{4}$ concentration in PGSW was tripled, the oil recovery increased by $7.34 \%$ compared to PGSW. Accordingly, depending on the conditions, it is possible to use PGSW so as to enhance the efficiency of oil recovery by removing $\mathrm{NaCl}$ or by increasing the concentration of $\mathrm{Na}_{2} \mathrm{SO}_{4}$ three times.
\end{abstract}

Keywords Smart water $\cdot$ Minimum IFT $\cdot$ Wettability $\cdot$ Zeta potential $\cdot$ Enhanced oil recovery

\section{Introduction}

Evidence has demonstrated that about $65 \%-70 \%$ of the oil in reservoirs is trapped when conventional oil recovery methods are used. In other words, these methods cannot overcome the capillary force in the porous medium and bring about significant oil production, especially in carbonate reservoirs. As a result, enhanced oil recovery (EOR) methods

Edited by Yan-Hua Sun

Amir Hossein Saeedi Dehaghani

asaeedi@modares.ac.ir

1 Department of Petroleum Engineering, Faculty of Chemical Engineering, Tarbiat Modares University, Tehran, Iran are used to extract remaining oil. Depending on reservoir conditions and oil characteristics, EOR methods, up to $40 \%$, can boost oil production (Sheng 2011, 2013).

In the last two decades, among EOR methods, smart water flooding has attracted special attention because not only is it a cost-effective method, but also it has fewer environmental problems (Alipour Tabrizy et al. 2011; Abubacker et al. 2017; Austad 2013; Darvish Sarvestani et al. 2019). Smart water flooding can be defined as a novel EOR technique in which the ionic composition of brine is changed by adding or removing ions to yield higher oil recovery. Smart water is obtained by adjusting and optimizing the concentration of ions in the base fluid or by adding a salt containing the ions that can change the balance of the oil/brine/rock system and improve oil recovery (Austad 2013; Abubacker et al. 2017; 
Darvish Sarvestani et al. 2019; Manshad et al. 2016). Smart water can change the wettability of the rock surface from hydrophobic to hydrophilic and reduce interfacial tension (IFT), hence allowing trapped oil to move easily (Al-sofi and Yousef 2013; Awolayo et al. 2016; Honarvar et al. 2020a; Manshad et al. 2017; Mohanty and Chandrasekhar 2013; Nowrouzi et al. 2019; Saeedi Dehaghani and Badizad 2019; Saeedi Dehaghani et al. 2020).

Smart water flooding has been the subject of numerous studies. For instance, Austad et al. (2012) reported that ultimate oil recovery in sandstone reservoirs could reach $75 \%$, provided that seawater ions are properly adjusted. Hognesen et al. (2005) performed imbibition tests on carbonate rock and found that $\mathrm{SO}_{4}{ }^{2-}$ plays an important role in altering wettability of the rock to water-wet; besides, oil recovery rises even further if the concentration of this ion is tripled in the injected brine. Exploring the effect of different ions as single components on IFT and contact angle, Gandomkar and Rahimpour (2017) stated that while $\mathrm{Mg}^{2+}$ and $\mathrm{SO}_{4}{ }^{2-}$ were able to make the limestone surface water-wet, $\mathrm{Ca}^{2+}, \mathrm{Na}^{+}$, and $\mathrm{K}^{+}$could not change wettability. They also reported that minimum IFT was obtained in the presence of $2,500 \mathrm{ppm}$ of $\mathrm{MgCl}_{2}$ and $\mathrm{Na}_{2} \mathrm{SO}_{4}$ salts. Al-Attar et al. (2013) also showed that in carbonate rock, by reducing the concentration of ions in the seawater to $5000 \mathrm{ppm}$, the oil recovery rose by $21.5 \%$ and the presence of $\mathrm{SO}_{4}{ }^{2-}$ in brine was crucial in changing the $\mathrm{pH}$ of the brine. It was also reported that increasing $\mathrm{Ca}^{2+}$ concentration in seawater did not result in a clear trend in IFT values and reduced oil recovery.

Performing smart water spontaneous imbibition, Fathi et al. (2010) showed that both divalent ions and monovalent cations play a key role in changing the wettability of chalk. They found that removing $\mathrm{Na}^{+}$from the seawater, rather than increasing its concentration, could be the best way to maximize oil recovery. In another study, Fathi et al. (2011) conducted core flooding in carbonates and observed that sweep efficiency was optimized when $\mathrm{NaCl}$ was removed from seawater, and $\mathrm{Na}_{2} \mathrm{SO}_{4}$ concentration was increased quadrupled. At a concentration of $1000 \mathrm{ppm}$, Amiri and Gandomkar (2019) examined the effects of various ions on IFT, wettability alteration, and recovery factor. The results revealed that although $\mathrm{MgSO}_{4}$, compared to $\mathrm{MgCl}_{2}$, increased IFT values and altered wettability from strongly water-wet to weakly water-wet, oil recovery was improved by the occurrence of the snap-off phenomenon. They also found that $\mathrm{NaCl}$ and $\mathrm{KCl}$ did not alter wettability, and limestone remained in the same oil-wet state. Adding $\mathrm{NaCl}, \mathrm{Na}_{2} \mathrm{SO}_{4}$, and $\mathrm{CaCl}_{2}$ to optimized seawater and examining changes in IFT and contact angle, Rahimi et al. (2020) reported that increasing the concentration of each ion led to an increasing trend followed by a decrease in IFT values. In addition, increasing the concentration of $\mathrm{Ca}^{2+}$ and $\mathrm{Na}^{+}$in optimized seawater raised contact angle, but increasing $\mathrm{SO}_{4}{ }^{2-}$ concentration caused a strongly water-wet state. Moreover, Kakati and Sangwai (2018) suggested that the type of oil affects the results of smart water flooding; thus, compared to divalent cations, monovalent cations are more effective in reducing IFT and changing wettability when $n$-alkanes hydrocarbons are utilized. Kedar and Bhagwat (2018) noted that $\mathrm{MgCl}_{2}$ was more capable of reducing IFT compared to $\mathrm{CaCl}_{2}$ and $\mathrm{NaCl}$. Also, Lashkarbolooki et al. (2014) investigated the impact of various ions, utilizing oil which contained a high percentage of asphaltene, on IFT and wettability alteration and reported that $\mathrm{MgCl}_{2}$ led to the lowest IFT; moreover, they reported, if divalent cations were bonded with $\mathrm{SO}_{4}{ }^{2-}$ rather than $\mathrm{Cl}^{-}$, it could prevent them from reducing IFT. They also found that although increasing ion concentration leads to an increase in contact angle, it leaves wettability within the range of waterwet conditions. Furthermore, Fattahi Mehraban et al. (2019) reported reductions in the contact angle when the temperature increases to $90{ }^{\circ} \mathrm{C}$, and $\mathrm{SO}_{4}{ }^{2-}$ is the most determining ion to change the wettability towards a more water-wet state.

In addition, Lashkarbolooki and Ayatollahi (2018) reported that the IFT of the crude oil-brine system depends on the weight percentage of resin and asphaltene in the oil and the oil aromaticity; thus, heightened resin aromaticity increases the impact of resin on IFT. Naeli et al. (2016) studied IFT changes caused by increasing the concentration of $\mathrm{CaCl}_{2}$ and $\mathrm{Na}_{2} \mathrm{SO}_{4}$ in diluted seawater. The results illustrated that increasing $\mathrm{Ca}^{2+}$ concentration first reduces and then increases IFT, but increasing $\mathrm{SO}_{4}{ }^{2-}$ concentration initially increases then reduces IFT. Nowrouzi et al. (2018) also examined the combined effect of different salts on IFT and contact angle, and their results indicated that using $\mathrm{MgCl}_{2}$ and $\mathrm{K}_{2} \mathrm{SO}_{4}$ together causes the lowest IFT. In addition, the contact angle reaches its lowest point because of the combined use of $\mathrm{MgSO}_{4}$ and $\mathrm{CaCl}_{2}$. In another study, Lashkarbolooki et al. (2017) found that $\mathrm{NaCl}$ and $\mathrm{KCl}$ exhibit different behavior in changing wettability, such that contact angle decreases by increasing $\mathrm{KCl}$ concentration or reducing $\mathrm{NaCl}$ concentration. Moreover, Zaheri et al. (2020) reported that the concentration of $\mathrm{CaCl}_{2}$ in formation water $(\mathrm{FW})$ can play an important role in wettability alteration.

It is worth mentioning that most of the previous studies have examined the effect of ions on IFT and wettability alteration when they have been used alone or binary in distilled water. Thus, the impact of each ion in a mixture of salts is still unclear. Moreover, there are no studies thoroughly investigating the effect of altering the concentration of specific ions in the Persian Gulf seawater (PGSW) to determine the composition and ionic strength that could optimally improve oil recovery. Given that the Persian Gulf basin has multiple oil reservoirs, each of which can benefit from the injection of seawater, we aim at determining which ion in PGSW minimizes IFT and contact angle and maximizes the ultimate oil recovery. To 
this end, we first study IFT changes owing to altering the concentration of $\mathrm{NaCl}, \mathrm{KCl}, \mathrm{MgCl}_{2}, \mathrm{CaCl}_{2}$, and $\mathrm{Na}_{2} \mathrm{SO}_{4}$ in PGSW. Then, for each of the ions at points where IFT is minimized, we perform contact angle and zeta potential tests in order to assess wettability alteration. Finally, a micromodel test is conducted to identify the amount of oil recovery at optimal concentrations.

\section{Materials and methods}

Each experiment was repeated three times for each concentration, and the mean values for each test were recorded. All experiments were carried out under ambient temperature and pressure conditions.

\subsection{Materials}

Table 1 shows the salts used in this study. The salts, in different concentrations, were used to generate $\mathrm{FW}$, PGSW, and smart water. Table 2 shows the compositions of PGSW and FW. Additionally, the crude oil used in this study was taken from one of the Iranian oil reservoirs. Properties and components of this oil are reported in Table 3. Besides, a mixture of hexamethyldisilane and toluene was used to make the micromodel oil-wet. Methanol was used to alter the wettability of the micromodel and to wash the salts from the rock specimens. It should be noted that all the materials were purchased from Merck Company (Germany).

\subsection{Brine and rock preparation}

Once the salt required for each solution was weighed using a digital scale, it was poured into a beaker containing distilled water; the solution was then mixed in a stirrer for $30 \mathrm{~min}$. In addition, the carbonate rock used in this study was collected from one of the rock formations in the southwestern Iran. First, the rock was cut into thin pieces so that it can be used in the contact angle test. The rock samples were washed with toluene and methanol to remove oil and salt, respectively; next, distilled water was used to remove toluene and methanol from the washed rock. Then, the rock specimens were placed in an oven for 1 day to dry at $65^{\circ} \mathrm{C}$. Next, the dried rock specimens were immersed in the $\mathrm{FW}$ solution. Afterwards, the rock specimens were immersed in oil at $90{ }^{\circ} \mathrm{C}$ for 15 days in order to become oil-wet. After making the rock samples oil-wet, for each salt, the solution was prepared at optimal concentration obtained from IFT tests. Next, the rock specimens were immersed in the prepared solutions for two weeks.

\subsection{IFT, contact angle and zeta potential measurements}

The pendant drop method was used to measure IFT. In this method, the shape of an oil droplet, the fluid density, gravity force, and the size of the needle were employed to evaluate IFT. It should be noted that this method has received wide currency among researchers since it can precisely measure IFT values (Saeedi Dehaghani et al. 2020; Honarvar et al. 2020a; Lashkarbolooki and Ayatollahi 2018; Manshad et al. 2016; Nowrouzi et al. 2019; Lashkarbolooki et al. 2014). In this IFT

Table 1 Properties of different salts

\begin{tabular}{llccc}
\hline Salt & Symbol & Molecular weight, $\mathrm{g} / \mathrm{mol}$ & Solubility in water, $\mathrm{g} / 100 \mathrm{~cm}^{3}$ & Density, $\mathrm{g} / \mathrm{cm}^{3}$ \\
\hline Potassium chloride & $\mathrm{KCl}$ & 74.55 & 34.02 & 1.98 \\
Sodium chloride & $\mathrm{NaCl}$ & 58.44 & 35.89 & 2.16 \\
Calcium chloride & $\mathrm{CaCl}_{2}$ & 110.99 & 74.50 & 2.15 \\
Magnesium chloride & $\mathrm{MgCl}_{2} \cdot 6 \mathrm{H}_{2} \mathrm{O}$ & 230.31 & 20.30 & 2.32 \\
Sodium sulfate & $\mathrm{Na}_{2} \mathrm{SO}_{4}$ & 142.04 & 19.50 & 2.66 \\
Sodium bicarbonate & $\mathrm{NaHCO}_{3}$ & 84.01 & 9.60 & 2.20 \\
Strontium chloride & $\mathrm{SrCl}_{2}$ & 158.53 & 53.80 & 3.05 \\
\hline
\end{tabular}

Table 2 Compositions of formation water and Persian Gulf seawater

\begin{tabular}{|c|c|c|c|c|c|c|c|c|c|}
\hline \multirow[t]{2}{*}{ Water } & \multicolumn{8}{|c|}{ Ion content, \% } & \multirow{2}{*}{$\begin{array}{l}\text { Ionic } \\
\text { strength, } \\
\text { mol/L }\end{array}$} \\
\hline & $\mathrm{K}^{+}$ & $\mathrm{Sr}^{2+}$ & $\mathrm{HCO}_{3}^{-}$ & $\mathrm{Na}^{+}$ & $\mathrm{Ca}^{2+}$ & $\mathrm{Mg}^{2+}$ & $\mathrm{Cl}^{-}$ & $\mathrm{SO}_{4}{ }^{2-}$ & \\
\hline PGSW & 399 & 3 & 166 & 12,000 & 440 & 1632 & 22,358 & 3110 & 0.785 \\
\hline FW & 1986 & 547 & 579 & 42,215 & 5032 & 759 & 78,421 & 635 & 2.117 \\
\hline
\end{tabular}


Table 3 Properties and components of oil sample

Component, $\mathrm{mol} \%$

\begin{tabular}{|c|c|c|c|c|c|c|c|c|c|c|}
\hline $\mathrm{C}_{1}$ & $\mathrm{C}_{2}$ & $\mathrm{C}_{3}$ & $i-\mathrm{C}_{4}$ & $n-\mathrm{C}_{4}$ & $i-\mathrm{C}_{5}$ & $n-\mathrm{C}_{5}$ & $\mathrm{C}_{6}$ & $\mathrm{C}_{7}$ & $\mathrm{C}_{8}$ & $\mathrm{C}_{9+}$ \\
\hline 0.01 & 0.02 & 0.01 & 0.78 & 1.14 & 2.57 & 5.95 & 5.82 & 6.22 & 7.21 & 70.27 \\
\hline \multicolumn{3}{|c|}{ Viscosity@ $@ 2{ }^{\circ} \mathrm{C}, \mathrm{cP}$} & \multicolumn{4}{|c|}{ Acid number, $\mathrm{mg} \mathrm{KOH} / \mathrm{g}$ oil } & \multicolumn{2}{|c|}{ Asphaltene, $\%$} & \multicolumn{2}{|c|}{ Resin, \% } \\
\hline \multicolumn{3}{|l|}{4.97} & \multicolumn{4}{|l|}{0.56} & \multicolumn{2}{|l|}{2.9} & \multicolumn{2}{|l|}{7.5} \\
\hline
\end{tabular}

measurement, the oil droplet was suspended in the brine by means of a needle; then, Drop Shape Analysis Software (LabVIEW software) was used to calculate IFT from a photo which was taken by a high-resolution microscopic camera. Moreover, the sessile drop technique was used to investigate the contact angle. In this method, a drop of oil in the presence of brine was placed on the surface of the carbonate rock by a needle; once equilibrium was reached, a photograph was taken from the drop, and the contact angle was calculated using Digimizer Image Analysis Software.

The zeta potential was measured using a Zetasizer (ZEN 3600 , UK). To this end, the carbonated rock was ground to prepare micron-size powder. Then, in the related concentrations of smart water, the powder and brine were mixed and then sonicated by an ultrasonic device for half an hour. Finally, the zeta potential was measured by placing a special electrode in the mixture.

\subsection{Flooding tests}

In this study, a five-spot glass micromodel was fabricated. The micromodel pattern was copied from a thin section of carbonated rock using CorelDraw Software. The flooding setup included an injection pump, a light, a glass micromodel, a computer, a camera, and a waste container. The pattern, properties of the glass micromodel, and schematic of flooding setup are shown in Fig. 1. In order to perform the micromodel flooding, the oil sample was injected into the micromodel until it was saturated $100 \%$ with oil. Then, smart water was injected into the micromodel at a rate of $0.05 \mathrm{~mL} / \mathrm{h}$. It should be noted that this flow rate was chosen to avoid turbulence behavior in the micromodel (Ghalamizade Elyaderani et al. 2019). Next, the picture of micromodel was taken by a camera at constant time intervals to measure the oil recovery factor. Before each flooding test, the micromodel was made oil-wet by the following procedure (Mofrad and Saeedi Dehaghani 2020):

(1) The micromodel was saturated with a mixture containing $5 \%$ of hexamethyldisilane and $95 \%$ of toluene for $20 \mathrm{~min}$ in order to make the glass surface silicone coated.

(2) The micromodel was washed with methanol so as to eliminate siliconizing solution.
(3) The micromodel was dried in an oven at $200{ }^{\circ} \mathrm{C}$ for an hour to maintain the silicone coating.

\section{Results and discussion}

\subsection{Effect of PGSW with different salinities on IFT}

Five different salts, including $\mathrm{NaCl}, \mathrm{KCl}, \mathrm{MgCl}_{2}, \mathrm{CaCl}_{2}$, and $\mathrm{Na}_{2} \mathrm{SO}_{4}$, were used to evaluate the oil/brine IFT. First, the effect of each ion, prepared in distilled water separately, on IFT was examined.

Figure 2 presents the effect of different concentrations of monovalent cations on IFT. As can be seen, the IFT decreases and reaches its minimum as a result of increasing the concentration of each ion to $1000 \mathrm{ppm}$. Specifically, the IFT decreases by 2.52 and $2.47 \mathrm{mN} / \mathrm{m}$ in the cases of $\mathrm{Na}^{+}$ and $\mathrm{K}^{+}$, respectively. Then, as the concentration of these two ions increases to $10,000 \mathrm{ppm}$, the IFT rises and reaches its maximum. Finally, the IFT declines if the concentration exceeds 10,000 ppm. For example, according to Fig. 2, $\mathrm{Na}^{+}$ shows an IFT value of $30.65 \mathrm{mN} / \mathrm{m}$ at a concentration of $10,000 \mathrm{ppm}$, and increasing the concentration to $40,000 \mathrm{ppm}$ results in an IFT value of $27.27 \mathrm{mN} / \mathrm{m}$.

Figure 3 illustrates the effect of divalent ions on IFT. According to Fig. 3, increasing the concentration of each divalent ion from 0 to $1000 \mathrm{ppm}$ reduces the IFT. The IFT decreases by $4.69,1.67$, and $2.63 \mathrm{mN} / \mathrm{m}$ for $\mathrm{Ca}^{2+}, \mathrm{Mg}^{2+}$, and $\mathrm{SO}_{4}{ }^{2-}$, respectively. The minimum IFT occurs at a concentration of $1000 \mathrm{ppm}$. At concentrations above $1000 \mathrm{ppm}$, the IFT rises, reaching a maximum at a certain concentration. Thus, the maximum IFT values for $\mathrm{Mg}^{2+}, \mathrm{Ca}^{2+}$, and $\mathrm{SO}_{4}{ }^{2-}$ occur at $10,000,5000$, and $10,000 \mathrm{ppm}$, respectively. It should be noted that a further increase in divalent ion concentration, above the concentration in which the maximum IFT occurs, causes the IFT to decrease. Comparing the capacity of all ions in minimizing IFT suggests that $\mathrm{Ca}^{2+}$ causes the highest IFT reduction, which is in line with the results of Honarvar et al. (2020b).

According to Figs. 2 and 3, it can be seen that the rising and falling trends in IFT values are the same when each of the ions is present individually in distilled water. The ion concentration range used in this study could be divided into 


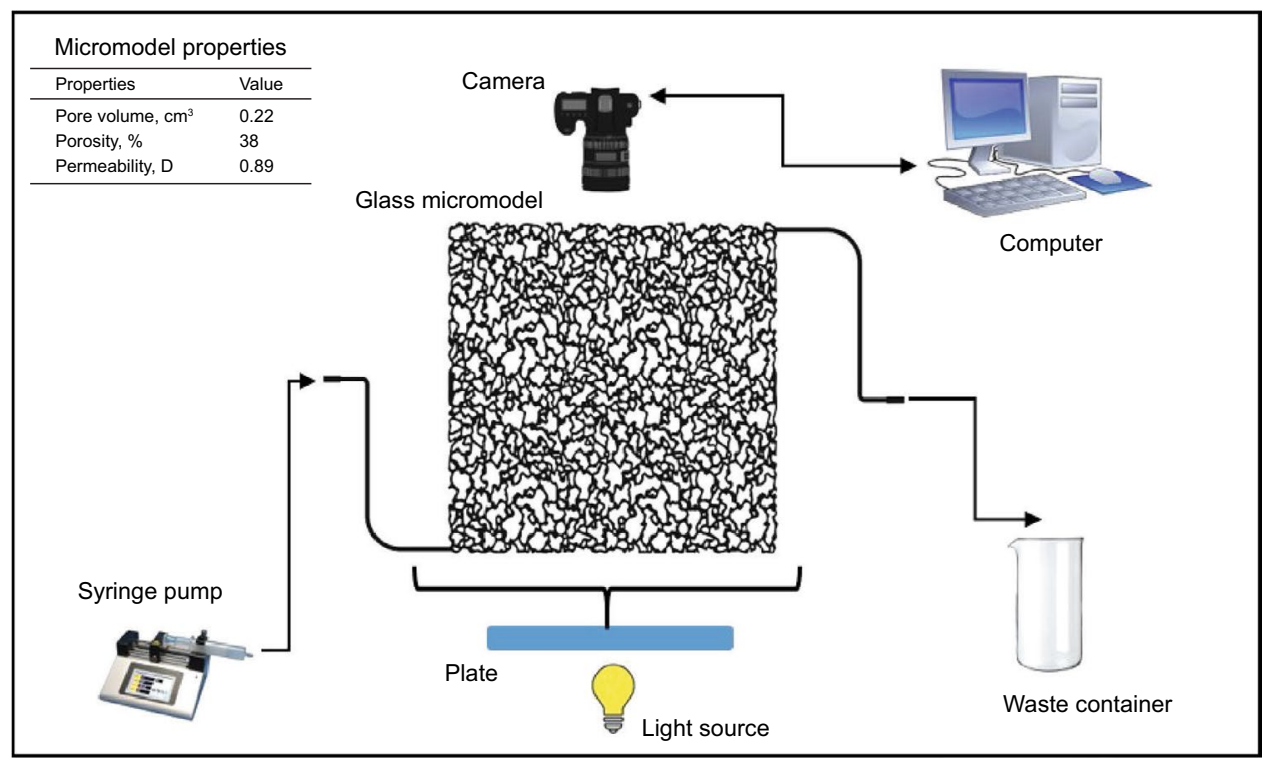

Fig. 1 Schematic of the micromodel setup and properties of the glass micromodel

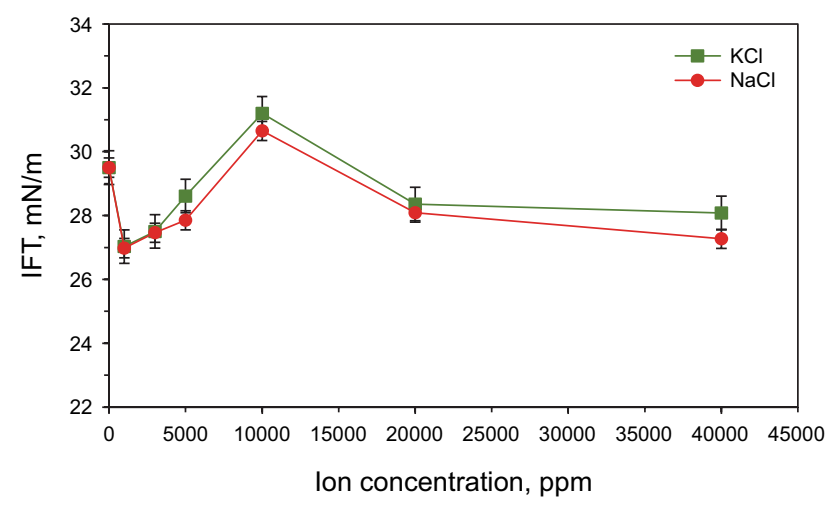

Fig. 2 Effect of monovalent ions on IFT between distilled water and oil

3 regions; thus, IFT decreased, increased, and decreased in Region 1, 2, and 3, respectively (Fig. 4). Based on Gibb's adsorption correlation, there is a relationship between IFT and surface excess concentration, such that if the surface excess is positive, the IFT reduction is visible and vice versa (Honarvar et al. 2020a; Lashkarbolooki et al. 2014; Rahimi et al. 2020).

In Region 1, where a low concentration of ions is present in the solution (brine with a concentration below $1000 \mathrm{ppm}$ ), the ions tend to migrate from the solution and stay at the water/oil interface. When the ions are placed at the water/ oil interface, two things happen. First, the surface excess concentration of ions increases, leading to a decrease in IFT. Second, natural surface-active agents in the oil such as polar asphaltenes move toward the interface; consequently, the surface excess concentration of asphaltenes becomes

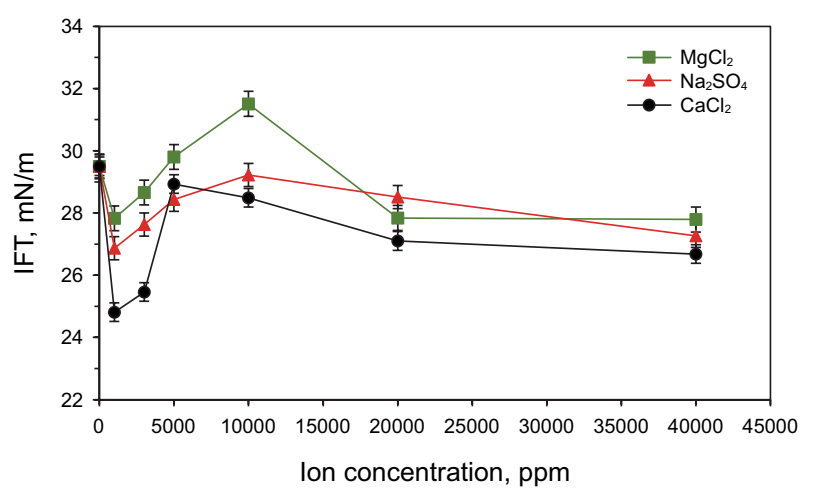

Fig. 3 Effect of divalent ions on IFT between distilled water and oil

positive, thereby reducing IFT. Moreover, ions help improve the solubility of the polar component of oil based on the salting-in effect, resulting in the IFT reduction (RezaeiDoust et al. 2009). In addition, when ions migrate to the interface, they tend to form complex ions with polar agents and boost the solubility of asphaltenes. This, in turn, can lead to positive surface excess concentration and IFT reduction (Austad 2013; Lashkarbolooki et al. 2014). In short, in low salt concentrations, the two mechanisms of the salting-in effect and the surface excess concentration contribute to IFT reduction.

In Region 2, where the IFT begins to increase as the concentration of ions in the brine rises, the presence of more ions in the solution heightens only the bulk of brine concentration because the ions are unable to move to one side of the saturated interface and stay there. Consequently, the surface excess concentration becomes negative, and the IFT increases. Additionally, the presence of more than a 
certain number of ions in the aqueous phase makes it difficult for polar agents to dissolve in water. This phenomenon is called the salting-out effect (Fattahi Mehraban et al. 2019; Lashkarbolooki et al. 2014; Rahimi et al. 2020). As a result, some natural surface-active agents return to the bulk of oil from the interface, and the IFT rises owing to the negative quality of asphaltene surface excess concentration. Rostami et al. (2019) and Honarvar et al. (2020a) showed that when salinity rises in the solution, the free surface energy of the interface as a result of the reduction in molecular movement decreases, and, consequently, it causes an increase in the IFT values. Therefore, the IFT increase, in Region 2, can also be attributed to the reduction in molecular movement. Additionally, as ions are placed in the brine, water molecules form hydrogen bonds with a cage-like structure around the ions. The formed hydrogen bonds can be broken as a result of the contact between the brine and the oil phase. Thus, ions tend to return to the bulk of the solution because of energy created at the interface (Kumar 2012; Lashkarbolooki et al. 2014). Consequently, the IFT increases owing to the decreased number of ions at the interface and the negative surface excess concentration. Therefore, in Region 2 , the salting-out effect, negative quality of surface excess concentration, molecular movement variation, and hydrogen bond-breaking are the main causes of the IFT increase.

Finally, in Region 3, the addition of more salts leads to a reduction in IFT. This decrease in IFT is probably because although some polar agents move from the interface to the bulk of oil because of the salting-out effect, which reduces their accumulation at the interface, there are still a number of these agents at the water/oil interface. Afterward, due to the packing effect, remaining polar agents are neatly re-situated

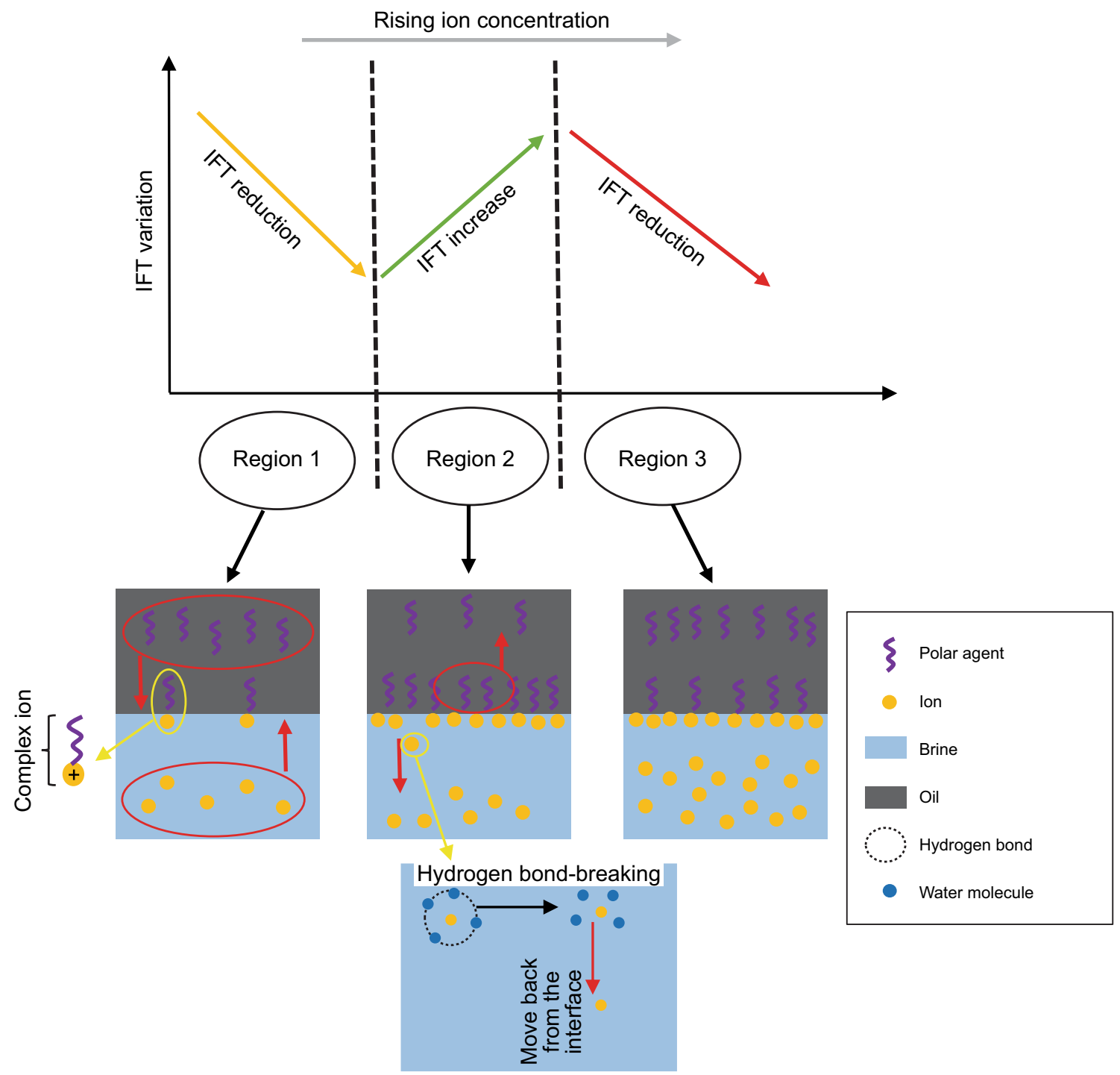

Fig. 4 Schematics of oil/water interface and IFT variations in different sections 
at the interface, and the IFT reduces (Lashkarbolooki et al. 2014). Hence, the reason for the reduction in IFT in Region 3 is explained by the packing effect.

After examining the effect of the presence and absence of each of the ions on IFT, we modified the concentration of ions in PGSW in order to determine IFT changes. Table 4 shows different concentrations of ions in PGSW, related ionic strength, and their density applied to assess IFT. For each ion, we used four different concentrations, which were $0,2,3$, and 4 times the initial concentration (i.e., the concentrations existing in PGSW). Figure 5 depicts the effect of PGSW with different concentrations of monovalent ions on IFT. By increasing the concentration of $\mathrm{Na}^{+}$or $\mathrm{K}^{+}$in the seawater, the IFT first rises and then falls slightly, and a minimum IFT occurs when $\mathrm{NaCl}$ or $\mathrm{KCl}$ is removed from the seawater. In fact, the minimum value of IFT was obtained in $\mathrm{SWONaCl}(26.29 \mathrm{mN} / \mathrm{m})$ and $\mathrm{SWOKCl}(26.56 \mathrm{mN} / \mathrm{m})$. In addition, increasing the concentration of $\mathrm{Na}^{+}$up to 2 times $(\mathrm{SW} 2 \mathrm{NaCl})$ and $\mathrm{K}^{+}$up to 3 times $(\mathrm{SW} 3 \mathrm{KCl})$ in PGSW increases the IFT by 5.01 and $2.35 \mathrm{mN} / \mathrm{m}$, respectively. It should be noted that although quadrupling the concentration of each monovalent ion reduces IFT, the resulting decrease is still much higher than the minimum IFT obtained by removing each of the salts in PGSW. The reason could be that the lack of $\mathrm{NaCl}$ or $\mathrm{KCl}$ in the seawater enables $\mathrm{Ca}^{2+}$, $\mathrm{Mg}^{2+}$, and $\mathrm{SO}_{4}{ }^{2-}$ to be placed more easily at the water/oil interface and further reduce IFT. In other words, by removing these salts, divalent ions could migrate to the double layer and react with polar agents, thereby reducing IFT. In terms of ionic strength, as shown in Table 4, it can be seen that removing $\mathrm{Na}^{+}$from PGSW decreases ionic strength from 0.785 to $0.334 \mathrm{~mol} / \mathrm{L}$. This decrease in ionic strength can contribute to improving the solubility of polar agents and IFT reduction. However, eliminating $\mathrm{K}^{+}$from PGSW, leading to minimum IFT, does not significantly change the ionic strength, decreasing only by $0.025 \mathrm{~mol} / \mathrm{L}$ as compared to PGSW. Moreover, although SWONaCl and SWOKCl solutions have different ionic strengths, a minimum IFT occurs in each mentioned solution. Therefore, it can be inferred that even though the reduction of ionic strength is crucial to have minimum IFT, other factors such as the oil composition, type of ion, and its activity can play an important role in reducing IFT. In the case of the effect of monovalent ions on IFT, previous studies reported that when $\mathrm{NaCl}$ or $\mathrm{KCl}$ is utilized individually or binary with other divalent ions in distilled water, IFT values reduce (Honarvar et al. 2020a; Kakati and Sangwai 2018; Lashkarbolooki and Ayatollahi 2018; Lashkarbolooki et al. 2014; Nowrouzi et al. 2018). However, the results of our study showed that the minimum IFT occurred when $\mathrm{Na}^{+}$or $\mathrm{K}^{+}$was eliminated from the smart water, and increasing concentration of monovalent ions could cause the IFT values to increase.

Table 4 Persian Gulf seawater with varied salt concentrations

\begin{tabular}{|c|c|c|c|c|c|c|c|c|c|c|}
\hline \multirow[t]{2}{*}{ Solution } & \multirow[t]{2}{*}{ Density, $\mathrm{g} / \mathrm{cm}^{3}$} & \multicolumn{8}{|c|}{ Ion concentration in seawater, ppm } & \multirow{2}{*}{$\begin{array}{l}\text { Ion } \\
\text { strength, } \\
\text { mol/L }\end{array}$} \\
\hline & & $\mathrm{Na}^{+}$ & $\mathrm{Ca}^{2+}$ & $\mathrm{Mg}^{2+}$ & $\mathrm{K}^{+}$ & $\mathrm{SO}_{4}^{2-}$ & $\mathrm{HCO}_{3}{ }^{-}$ & $\mathrm{Sr}^{2+}$ & $\mathrm{Cl}^{-}$ & \\
\hline SW0NaCl & 0.9933 & 1452 & 440 & 1632 & 399 & 3110 & 166 & 3 & 6064 & 0.334 \\
\hline $\mathrm{SW} 2 \mathrm{NaCl}$ & 1.0275 & 22,511 & 440 & 1632 & 399 & 3110 & 166 & 3 & 38,653 & 1.252 \\
\hline $\mathrm{SW} 3 \mathrm{NaCl}$ & 1.044 & 33,059 & 440 & 1632 & 399 & 3110 & 166 & 3 & 54,957 & 1.711 \\
\hline $\mathrm{SW} 4 \mathrm{NaCl}$ & 1.0594 & 43,607 & 440 & 1632 & 399 & 3110 & 166 & 3 & 71,241 & 2.17 \\
\hline $\mathrm{SWOCaCl}_{2}$ & 1.0104 & 12,000 & 0 & 1632 & 399 & 3110 & 166 & 3 & 21,577 & 0.76 \\
\hline $\mathrm{SW} 2 \mathrm{CaCl}_{2}$ & 1.0119 & 12,000 & 880 & 1632 & 399 & 3110 & 166 & 3 & 23,139 & 0.826 \\
\hline $\mathrm{SW} 3 \mathrm{CaCl}_{2}$ & 1.0123 & 12,000 & 1320 & 1632 & 399 & 3110 & 166 & 3 & 23,920 & 0.859 \\
\hline $\mathrm{SW} 4 \mathrm{CaCl}_{2}$ & 1.0135 & 12,000 & 2560 & 1632 & 399 & 3110 & 166 & 3 & 24,701 & 0.892 \\
\hline $\mathrm{SWOMgCl}_{2}$ & 1.008 & 12,000 & 440 & 0 & 399 & 3110 & 166 & 3 & 17,601 & 0.592 \\
\hline $\mathrm{SW} 2 \mathrm{MgCl}_{2}$ & 1.0113 & 12,000 & 440 & 3265 & 399 & 3110 & 166 & 3 & 27,115 & 0.994 \\
\hline $\mathrm{SW} 3 \mathrm{MgCl}_{2}$ & 1.0184 & 12,000 & 440 & 4896 & 399 & 3110 & 166 & 3 & 31,872 & 1.195 \\
\hline $\mathrm{SW} 4 \mathrm{MgCl}_{2}$ & 1.0204 & 12,000 & 440 & 6528 & 399 & 3110 & 166 & 3 & 36,629 & 1.396 \\
\hline SW0KCl & 1.0106 & 12,000 & 440 & 1632 & 0 & 3110 & 166 & 3 & 22,003 & 0.783 \\
\hline $\mathrm{SW} 2 \mathrm{KCl}$ & 1.0117 & 12,000 & 440 & 1632 & 798 & 3110 & 166 & 3 & 22,713 & 0.803 \\
\hline SW3KCl & 1.0123 & 12,000 & 440 & 1632 & 1197 & 3110 & 166 & 3 & 23,068 & 0.813 \\
\hline SW4KCl & 1.0135 & 12,000 & 440 & 1632 & 1596 & 3110 & 166 & 3 & 23,423 & 0.823 \\
\hline $\mathrm{SWONa}_{2} \mathrm{SO}_{4}$ & 1.0088 & 10,622 & 440 & 1632 & 399 & 0 & 166 & 3 & 22,358 & 0.703 \\
\hline $\mathrm{SW}_{2} \mathrm{Na}_{2} \mathrm{SO}_{4}$ & 1.016 & 13,379 & 440 & 1632 & 399 & 6220 & 166 & 3 & 22,358 & 0.883 \\
\hline $\mathrm{SW} 3 \mathrm{Na}_{2} \mathrm{SO}_{4}$ & 1.0197 & 14,758 & 440 & 1632 & 399 & 9330 & 166 & 3 & 22,358 & 0.973 \\
\hline 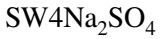 & 1.0239 & 16,137 & 440 & 1632 & 399 & 12,440 & 166 & 3 & 22,358 & 1.063 \\
\hline
\end{tabular}




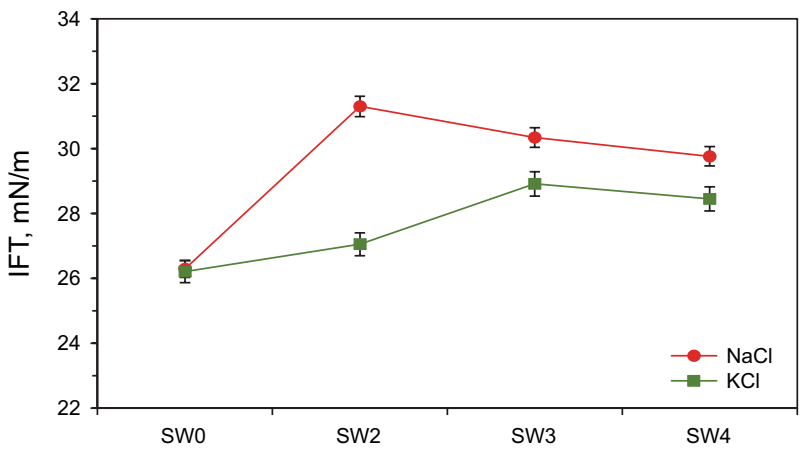

Fig. 5 Effect of monovalent ions spiking of seawater on IFT

Figure 6 illustrates the effect of PGSW with different concentrations of divalent ions on IFT. As can be seen, as the concentrations of $\mathrm{CaCl}_{2}, \mathrm{MgCl}_{2}$, and $\mathrm{Na}_{2} \mathrm{SO}_{4}$ are increased, the IFT initially declines and then increases. $\mathrm{Mg}^{2+}, \mathrm{Ca}^{2+}$, and $\mathrm{SO}_{4}{ }^{2-}$ are potential determining ions (PDI); therefore, their presence in seawater can play a significant role in reducing IFT. To put it differently, when the concentration of PDI increases in PGSW, they can react with carboxyls at the oil/water interface, and this, in turn, can lead to an increase in the solubility of carboxyls in both oil and water phases. Thus, the IFT decreases to a minimum value. However, when the IFT reaches its minimum value, a further increase in the concentration of PDI can bring about an increase in IFT. This increase in IFT values can be attributed to two reasons. The first reason would be that the mechanism of the saltingout effect is activated if the concentration of PDI increases more than a certain value. In other words, as high concentrations of $\mathrm{Ca}^{2+}, \mathrm{Mg}^{2+}$, and $\mathrm{SO}_{4}{ }^{2-}$ are present in the proximity to the interface, the solubility of polar agents decreases, and water molecules are unable to balance the polarization of divalent ions and carboxyls. Therefore, polar agents return from the interface to the bulk of the oil phase, leading to the negative surface excess concentration and higher IFT. Another possible reason might be that molecular movement can greatly decrease at a high concentration of PDI. Thus, the free surface energy of the interface can diminish, and, as a result, the IFT increases. The minimum IFT for $\mathrm{Ca}^{2+}, \mathrm{Mg}^{2+}$, and $\mathrm{SO}_{4}{ }^{2-}$, corresponding to $29.95,27.45$, and $26.96 \mathrm{mN} / \mathrm{m}$, respectively, occurs at 3,2 , and 3 times the initial concentration. Furthermore, according to the results, $\mathrm{SO}_{4}{ }^{2-}$ can cause a further reduction in IFT as compared to $\mathrm{Ca}^{2+}$ and $\mathrm{Mg}^{2+}$. Also, according to Table 4, the ionic strength for $\mathrm{SW} 3 \mathrm{Na}_{2} \mathrm{SO}_{4}, \mathrm{SW} 3 \mathrm{CaCl}_{2}$, and $\mathrm{SW} 2 \mathrm{MgCl}_{2}$ was respectively $0.973,0.859$, and $0.994 \mathrm{~mol} / \mathrm{L}$. Accordingly, although tripling the concentration of $\mathrm{SO}_{4}{ }^{2-}$ leads to the lowest IFT compared to the other divalent ions $\mathrm{Mg}^{2+}$ and $\mathrm{Ca}^{2+}$ ), SW3 $3 \mathrm{Na}_{2} \mathrm{SO}_{4}$ has greater ionic strength. As a result, it can be concluded that seawater with lower ionic strength may not result in minimum IFT, and other factors mentioned before should be considered alongside ionic strength. For example, in this research, even though the $\mathrm{SW} 3 \mathrm{Na}_{2} \mathrm{SO}_{4}$ solution had greater ionic strength compared to $\mathrm{SW} 3 \mathrm{CaCl}_{2}$, it produced lower IFT values. This issue can be rooted in the fact that $\mathrm{SO}_{4}{ }^{2-}$ has greater ion activity than $\mathrm{Ca}^{2+}$, and therefore it has more ability to reduce IFT to minimum values.

The results of IFT tests suggest that even though the absence of monovalent ions such as $\mathrm{Na}^{+}$and $\mathrm{K}^{+}$in seawater leads to a decrease in IFT values, the presence of divalent ions is necessary for reducing IFT. Because divalent ions, which are active, can form complex ions with polar agents that come to the water/oil interface from the bulk of the oil, and solubility of polar agents increases. Therefore, it can be inferred that divalent ions have a great ability to reduce IFT and, consequently, their presence in smart water is vital. In the case of the effect of divalent ions on IFT, according to previous research (Honarvar et al. 2020a; Kakati and Sangwai 2018; Lashkarbolooki and Ayatollahi 2018; Lashkarbolooki et al. 2014; Nowrouzi et al. 2018), increasing concentration of the divalent ions can diminish IFT values when $\mathrm{Mg}^{2+}, \mathrm{Ca}^{2+}$, and $\mathrm{SO}_{4}{ }^{2-}$ are utilized individually or in pair in distilled water. Moreover, our results also illustrated that they are capable of reducing IFT in the presence of other divalent and monovalent ions.

According to IFT results, the optimal concentrations for $\mathrm{NaCl}, \mathrm{KCl}, \mathrm{MgCl}_{2}, \mathrm{CaCl}_{2}$, and $\mathrm{Na}_{2} \mathrm{SO}_{4}$ occur in SW0NaCl, SW0KCl, SW2 $\mathrm{MgCl}_{2}, \mathrm{SW} 3 \mathrm{CaCl}_{2}$, and $\mathrm{SW} 3 \mathrm{Na}_{2} \mathrm{SO}_{4}$ solutions, respectively. The IFT between oil and diluted PGSW and FW was calculated for comparison purposes. The IFT values for FW, PGSW, doubly diluted PGSW (SW2d), and tenfold diluted PGSW (SW10d) are 31.14, 30.40, 27.11, and $33.36 \mathrm{mN} / \mathrm{m}$, respectively (Table 5 ). Based on Table 5 and Figs. 5 and 6, removing $\mathrm{NaCl}$ from PGSW or tripling the concentration of $\mathrm{Na}_{2} \mathrm{SO}_{4}$ reduces IFT more than does diluted PGSW. The IFT values for SW2d, SW3 $\mathrm{Na}_{2} \mathrm{SO}_{4}$, and $\mathrm{SW} 0 \mathrm{NaCl}$ solutions are $27.11,26.96$, and $26.29 \mathrm{mN} / \mathrm{m}$, respectively, indicating that smart water flooding has a better performance in this regard.

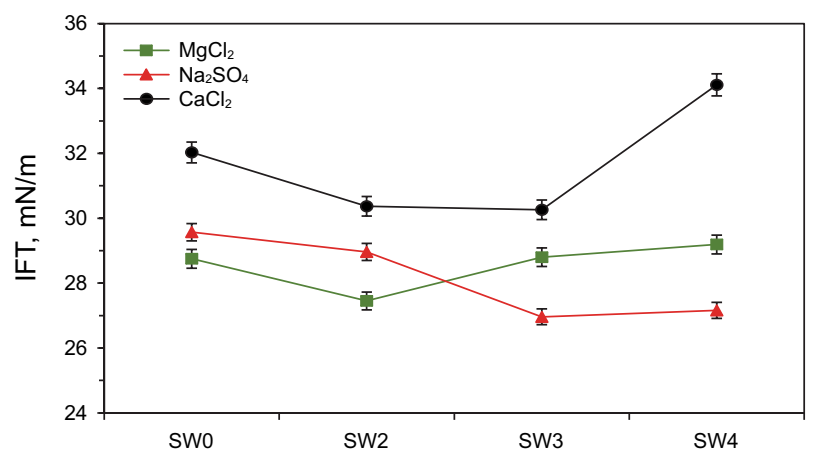

Fig. 6 Effect of divalent ions spiking of seawater on IFT 


\subsection{Effect of PGSW with different salinities on contact angle and zeta potential}

In order to evaluate wettability alteration, we measured the contact angle for each salt at optimal concentrations obtained from IFT tests. After the rock specimens became oil-wet, the average contact angle was $123^{\circ}$, which confirms that the rock specimens are oil-wet. Table 6 presents the shape of the droplets in equilibrium, contact angle values, ionic strength, and zeta potential at optimal concentrations. The contact angle values for PGSW, SW $3 \mathrm{CaCl}_{2}, \mathrm{SW} 0 \mathrm{NaCl}$, SW0KCl, SW2 $\mathrm{MgCl}_{2}$, and $\mathrm{SW} 3 \mathrm{Na}_{2} \mathrm{SO}_{4}$ solutions are $91^{\circ}, 85.8^{\circ}, 67.8^{\circ}, 81.7^{\circ}, 77.9^{\circ}$, and $70.2^{\circ}$, respectively. A weakly water-wet condition occurs when the contact angle is between $30^{\circ}$ and $75^{\circ}$, and a neutral-wet condition emerges when the contact angle is in the range of $75^{\circ}$ to $105^{\circ}$ (Meng et al. 2018).

According to Table 6, removing $\mathrm{NaCl}$ from the PGSW causes wettability to approach the weakly water-wet condition. There are main reasons for this change in wettability, as a result of eliminating $\mathrm{NaCl}$. Firstly, when the concentrations of the monovalent ions decrease in PGSW, the dissolution of carbonate rock occurs (Al-Nofli et al. 2018). In this case, calcium carbonate dissolves, and the rock surface becomes negatively charged based on the following reaction (Karimi et al. 2016):

$\mathrm{CaCO}_{3}(\mathrm{~s})+\mathrm{H}_{2} \mathrm{O} \leftrightarrow \mathrm{Ca}^{2+}+\mathrm{HCO}_{3}^{-}+\mathrm{OH}^{-}$

Therefore, more carboxyls can be detached from the surface of rock because of the repulsive force existing between negative charges of rock and carboxyls. Consequently, wettability can be changed to weakly water-wet, and this mechanism is shown in Fig. 7. Secondly, it should be mentioned that the ions in the brine are in contact with the rock surface through an electrical double layer which is formed by diffusive and stern layers, and they can be either adsorbed by the attractive force on the rock or driven away from the surface by the repulsive force (Lashkarbolooki et al. 2017; Shirazi et al. 2020). Therefore, when the brine has a high concentration of $\mathrm{NaCl}$, high levels of $\mathrm{Na}^{+}$in the diffusive layer are present, and less chance is given to divalent ions to be positioned in the electrical double layer so as to further reduce the contact angle due to their activity. Thus, once $\mathrm{NaCl}$ is eliminated from the seawater, the carbonate rock surface is more readily available to $\mathrm{Ca}^{2+}, \mathrm{Mg}^{2+}$, and $\mathrm{SO}_{4}{ }^{2-}$, which are active ions, and wettability, as a result of the expansion of the double layer, could change from oil-wet to weakly water-wet (Fig. 8). Finally, decreasing concentration of ions in seawater can give rise to the salting-in effect, and therefore more carboxyls can be desorbed from the surface (Karimi et al. 2016). In other words, reducing the concentration of ions in the brine leads to an increase in the solubility
Table 5 Effect of seawater, diluted seawater and formation water on IFT

\begin{tabular}{lll}
\hline Solution & IFT, $\mathrm{mN} / \mathrm{m}$ & $\begin{array}{l}\text { Suspended oil droplet } \\
\text { shape }\end{array}$ \\
\hline PGSW & $30.40 \pm 0.24$ \\
$\begin{array}{l}\text { SW2d (diluted } 2 \\
\text { times) }\end{array}$ & $27.11 \pm 0.19$ \\
SW10d (diluted & $33.36 \pm 0.11$ \\
10 times) & \\
FW & $31.14 \pm 0.31$
\end{tabular}

of the polar agents in water, and a further reduction can be seen in the contact angle values. Thus, when removing $\mathrm{NaCl}$ from the PGSW solution, the mechanism of the salting-in effect is activated, and the contact angle decreases further. It is noteworthy that as removing $\mathrm{Na}^{+}$from PGSW, the ionic strength reduces from 0.785 to $0.334 \mathrm{~mol} / \mathrm{L}$. Therefore, the adhesion of oil on the rock surface can be decreased, and this, in turn, can boost water-wetness conditions. However, eliminating $\mathrm{KCl}$ does not considerably change the contact angle, it only leads to a nine-degree reduction in this angle relative to PGSW and leaves wettability in the same neutralwet condition. The reason could be that the concentration of $\mathrm{K}^{+}$is low in PGSW, and removing it does not significantly affect wettability.

Also, even though doubling $\mathrm{MgCl}_{2}$ concentration reduces the contact angle by $13.1^{\circ}$ relative to PGSW, the neutral-wet condition remains in place. As discussed in the literature (Fathi et al. 2010; Karimi et al. 2016), as a result of the presence of anions and the dissolution process, $\mathrm{Mg}^{2+}$ can get closer to the rock surface since less positive charges are available on the rock surface. Therefore, $\mathrm{Mg}^{2+}$ can react with carboxyls and reduce contact angle. Besides, it can replace $\mathrm{Ca}^{2+}$ via ion exchange, and, as a result, this can detach oil droplets from the carbonate surface (Zhang and Austad 2006). Nevertheless, by comparison with SWONaCl in terms of wettability alteration, $\mathrm{SW} 2 \mathrm{MgCl}_{2}$ solution was unable to significantly reduce the contact angle, due to the 
Table 6 Effect of different smart water solutions on the contact angle and zeta potential

\begin{tabular}{|c|c|c|c|c|}
\hline Solution & Contact angle, degree & Ion strength, $\mathrm{mol} / \mathrm{L}$ & Oil droplet shape & Zeta potential, $\mathrm{mV}$ \\
\hline PGSW & $91.0 \pm 1.03$ & 0.785 & & $-2.7 \pm 0.17$ \\
\hline $\mathrm{SW} 3 \mathrm{CaCl}_{2}$ & $85.8 \pm 1.23$ & 0.859 & & $-2.4 \pm 0.13$ \\
\hline SWONaCl & $67.8 \pm 1.65$ & 0.334 & & $-4.9 \pm 0.21$ \\
\hline SW0KCl & $81.7 \pm 1.11$ & 0.783 & & $-3.7 \pm 0.19$ \\
\hline $\mathrm{SW} 2 \mathrm{MgCl}_{2}$ & $77.9 \pm 0.98$ & 0.994 & & $-2.3 \pm 0.15$ \\
\hline $\mathrm{SW} 3 \mathrm{Na}_{2} \mathrm{SO}_{4}$ & $70.2 \pm 1.44$ & 0.973 & & $-1.8 \pm 0.18$ \\
\hline
\end{tabular}
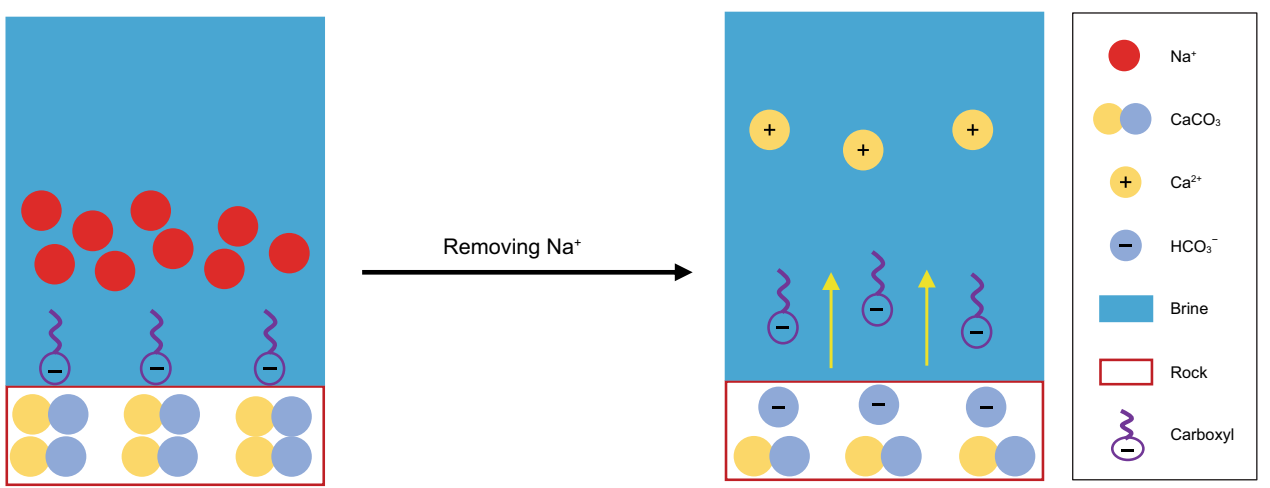

Fig. 7 Schematic of the mechanism of dissolution in the absence of $\mathrm{Na}^{+}$

high concentration of $\mathrm{Na}^{+}$in the double layer. To put it differently, the high concentration of $\mathrm{Na}^{+}$hindered the positive effects of $\mathrm{Mg}^{2+}$ from changing the wettability towards water-wet condition. Also, tripling the concentration of $\mathrm{Ca}^{2+}$ shows that wettability cannot be changed to water-wet condition. Because, more than a certain concentration of $\mathrm{Ca}^{2+}$, the salting-out effect is activated, and the contact angle does not change substantially (Rahimi et al. 2020). In other words, the solubility of polar agents can be decreased due to the high concentration of $\mathrm{Ca}^{2+}$ in the PGSW. In fact, as the concentration of $\mathrm{Ca}^{2+}$ increases in PGSW, a water structure, which is created as a result of hydrogen bonds formed between hydrophobic pieces of polar agents and water molecules, can be broken, and the solubility of polar agents is decreased. Thus, wettability cannot be altered to a water-wet state owing to the decreased solubility.

Like the effect of $\mathrm{NaCl}$ removal on wettability, increasing $\mathrm{Na}_{2} \mathrm{SO}_{4}$ concentration can alter the wettability of carbonate rock to weakly water-wet conditions. In smart water flooding, the carbonate rock surface can have positive charges (RezaeiDoust et al. 2009). Also, when the concentration of $\mathrm{SO}_{4}{ }^{2-}$ in PGSW increases, because of the adsorption of $\mathrm{SO}_{4}{ }^{2-}$ on it, the rock surface shifts from a surface with positive charges to a surface with negative charges. Therefore, in the presence of negative charges, divalent cations will be able to approach the surface of the rock and change wettability by replacing complex ions, formed between $\mathrm{Ca}^{2+}$ and carboxyls, with $\mathrm{Mg}^{2+}$ (Fathi et al. 2010; Rashid et al. 2015). Moreover, when anions and cations are present in the brine, ion-pairs can be formed. In other words, based on Eqs. (2) and (3), the formation of ion-pairs is between $\mathrm{Mg}^{2+}, \mathrm{Ca}^{2+}$, and $\mathrm{SO}_{4}{ }^{2-}$ (Moosavi et al. 2019).

$\mathrm{Mg}^{2+}+\mathrm{SO}_{4}^{2-}=\left[\mathrm{Mg}^{2+\ldots \ldots \ldots . . .} \mathrm{SO}_{4}^{2-}\right]$ 


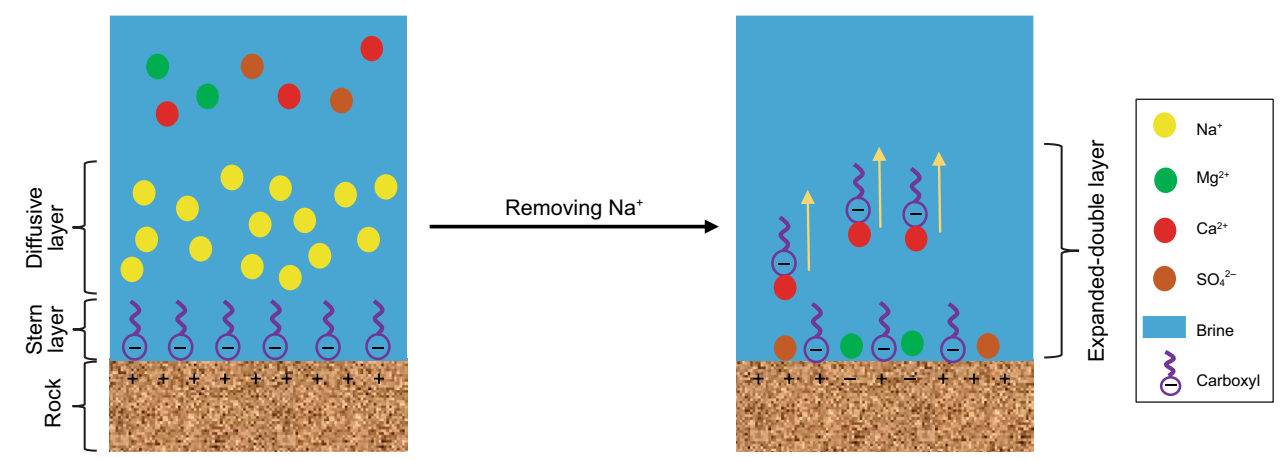

Fig. 8 Schematic of the expansion of double layer in the absence of $\mathrm{Na}^{+}$

$\mathrm{Ca}^{2+}+\mathrm{SO}_{4}^{2-}=\left[\mathrm{Ca}^{2+\ldots \ldots \cdots} \cdot \mathrm{SO}_{4}^{2-}\right]$

Therefore, as $\mathrm{SO}_{4}{ }^{2-}$ is adsorbed on the rock surface, owing to the formation of ion-pairs, more $\mathrm{Mg}^{2+}$ and $\mathrm{Ca}^{2+}$ are available in close proximity to the surface, and wettability can be further altered. It should be pointed out that the ionic strength values for $\mathrm{SW} 3 \mathrm{Na}_{2} \mathrm{SO}_{4}, \mathrm{SW} 3 \mathrm{CaCl}_{2}$, and $\mathrm{SW}_{2} \mathrm{MgCl}_{2}$ increase by $0.188,0.074$, and $0.209 \mathrm{~mol} / \mathrm{L}$, respectively. According to previous studies (Derkani et al. 2019), lowering the ionic strength values can enhance the water-wetness condition of the rock surface. Our results illustrate that although the ionic strength increases, the contact angle decreases. Thus, it can be inferred that the presence of PDI plays a prominent role in contact angel reduction, and wettability alteration can occur if the ionic strength rises.

As Table 6 shows, in order to evaluate the surface charge of rock for optimal concentrations, we calculated zeta potential at $-2.7 \mathrm{mV}$ when the carbonate rock was exposed to the PGSW solution. Following the removal of $\mathrm{NaCl}$ or $\mathrm{KCl}$, the zeta potential was -4.7 and $-3.7 \mathrm{mV}$, respectively. Therefore, the removal of monovalent ions from the PGSW solution increases the magnitude of the negative zeta potential, which is consistent with the results reported by Abbasi et al. (2020). However, as the concentration of $\mathrm{Mg}^{2+}$ in the PGSW solution is doubled, the negative charge on the rock surface is reduced just slightly. In this case, the zeta potential has changed from -2.7 to $-2.3 \mathrm{mV}$. A similar trend was observed for $\mathrm{SW} 3 \mathrm{CaCl}_{2}$. As the concentration of $\mathrm{Ca}^{2+}$ was tripled in PGSW, the zeta potential was altered from -2.7 to $-2.4 \mathrm{mV}$. In fact, increasing concentration of $\mathrm{Mg}^{2+}$ or $\mathrm{Ca}^{2+}$ owing to the adsorption of these ions onto the rock reduces the negative charge of the surface by a small amount.

Also, the zeta potential changes from -2.7 to $-1.8 \mathrm{mV}$ by tripling the concentration of $\mathrm{Na}_{2} \mathrm{SO}_{4}$ in PGSW. Some previous studies (Abbasi et al. 2020; Strand et al. 2006; Alroudhan et al. 2016; Kasha et al. 2015; Smallwood 1977; Mahani et al. 2017) show that there is a rise in the magnitude of the negative zeta potential as the $\mathrm{SO}_{4}{ }^{2-}$ concentration increases in seawater, which contradict our results.
However, Al-Hashim et al. (2018) reported that doubling the concentration of $\mathrm{SO}_{4}{ }^{2-}$ in seawater decreases the negative surface charge of carbonate rock. Therefore, their result for $\mathrm{SO}_{4}{ }^{2-}$ is in line with our results. This decline in the magnitude of the negative zeta potential can be attributed to two reasons. Firstly, because of electrostatic screening, above a specific concentration of $\mathrm{Na}_{2} \mathrm{SO}_{4}$, ions are unable to be adsorbed onto the rock surface, and increasing the $\mathrm{Na}_{2} \mathrm{SO}_{4}$ concentration causes the rock surface to have less negative charges (Awolayo and Sharma 2016). Secondly, the concentrations of divalent ions and their presence in seawater can have impacts on the affinity of ions towards the surface, and the zeta potential values can be changed from negative to positive even by an increase in the concentration of $\mathrm{SO}_{4}{ }^{2-}$ (Kasha et al. 2015).

\subsection{Micromodel flooding}

Micromodel flooding was performed at optimal concentrations obtained for each salt to evaluate oil recovery by smart water flooding. Figure 9 shows the ultimate oil recovery through the injection of different smart solutions at optimal concentrations. As a result of PGSW flooding, oil recovery was $23.22 \%$, which is the lowest oil recovery compared to other solutions. The ultimate oil recovery values for SWONaCl, SW0KCl, SW2 $\mathrm{MgCl}_{2}$, and SW3 $\mathrm{Na}_{2} \mathrm{SO}_{4}$ solutions were $33.34,27.12,28.44$, and $30.56 \%$, respectively. As can be seen, the $\mathrm{SW} 0 \mathrm{NaCl}$ solution exhibits the highest oil recovery because it has not only the lowest IFT but also the largest alteration of contact angle. In fact, the oil recovery was $10.12 \%$ higher than PGSW flooding. This is in line with the results reported by Fathi et al. (2010, 2011), Awolayo and Sharma (2016), and Puntervold et al. (2015). The oil recovery for PGSW without $\mathrm{K}^{+}$was about $6.5 \%$ less than PGSW without $\mathrm{Na}^{+}$. The difference in oil recovery of these two solutions, although IFT values are almost the same for both, is explained by the fact that the $\mathrm{SW} 0 \mathrm{NaCl}$ solution can cause a higher reduction in the contact angle; thus, it produces more oil in a more 
water-wet condition. In addition, the $\mathrm{SW} 3 \mathrm{Na}_{2} \mathrm{SO}_{4}$ solution increased oil recovery by $2.12 \%$ more than did the SW2 $\mathrm{MgCl}_{2}$ solution because it further reduced IFT and changed the wettability to a weakly water-water state. Figure 10 illustrates micromodel images after the injection of 1 pore volume (PV) of smart water for PGSW and SW0NaCl solutions. As shown, the $\mathrm{SW} 0 \mathrm{NaCl}$ solution, compared to PGSW, was able to improve the sweep efficiency, resulting in less trapped oil in the micromodel. Thus, the lowest IFT and contact angle were obtained for the $\mathrm{SW} 0 \mathrm{NaCl}$ solution, which allowed overcoming the capillary forces in the micromodel pores leading to more oil production. Therefore, removing $\mathrm{NaCl}$ or tripling the concentration of $\mathrm{Na}_{2} \mathrm{SO}_{4}$ can be the best possible option if one seeks to carry out smart water flooding by changing the concentration of salts in PGSW in order to improve oil recovery.

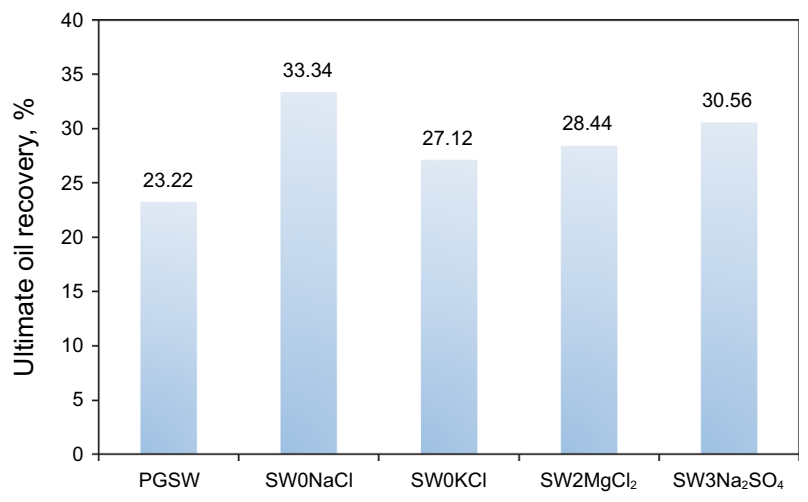

Fig. 9 Effect of different smart water solutions on the ultimate oil recovery

\section{Conclusions}

Based on the tests performed, which included IFT, contact angle, zeta potential, and micromodel tests, the following results can be inferred:

(1) When each ion was utilized separately in distilled water, $\mathrm{Ca}^{2+}$ showed a greater ability to reduce IFT to a minimum value. In the case of using different concentrations of monovalent and divalent ions in PGSW, eliminating $\mathrm{Na}^{+}$from PGSW resulted in the lowest IFT value.

(2) Although removing each of the monovalent ions $\left(\mathrm{K}^{+}\right.$ or $\mathrm{Na}^{+}$) from PGSW causes IFT reduction, increasing $\mathrm{Ca}^{2+}, \mathrm{Mg}^{2+}$, and $\mathrm{SO}_{4}{ }^{2-}$ concentrations in PGSW decreased IFT values. Thus, it can be stated that the absence of monovalent ions is of importance to decline IFT, and the presence of divalent ions plays a crucial role in reducing IFT. It should be noted that seawater with lower ionic strength may not result in minimum IFT, and other factors such as the presence of PDI can have a more positive effect on minimizing the IFT.

(3) The lowest contact angle was related to the solution from which $\mathrm{NaCl}$ was removed $\left(67.8^{\circ}\right)$. Additionally, among all the solutions evaluated, only $\mathrm{SWONaCl}$ and $\mathrm{SW} 3 \mathrm{Na}_{2} \mathrm{SO}_{4}$ could change surface wettability to weakly water-wet conditions, while the other solutions led to a neutral-wet condition.

(4) The removal of $\mathrm{NaCl}$ or $\mathrm{KCl}$ from PGSW caused the rock surface to have slightly higher negative charges. However, increasing the concentration of divalent ions $\left(\mathrm{Ca}^{2+}, \mathrm{Mg}^{2+}\right.$, and $\left.\mathrm{SO}_{4}{ }^{2-}\right)$ led to a reduction in the magnitude of the negative zeta potential.
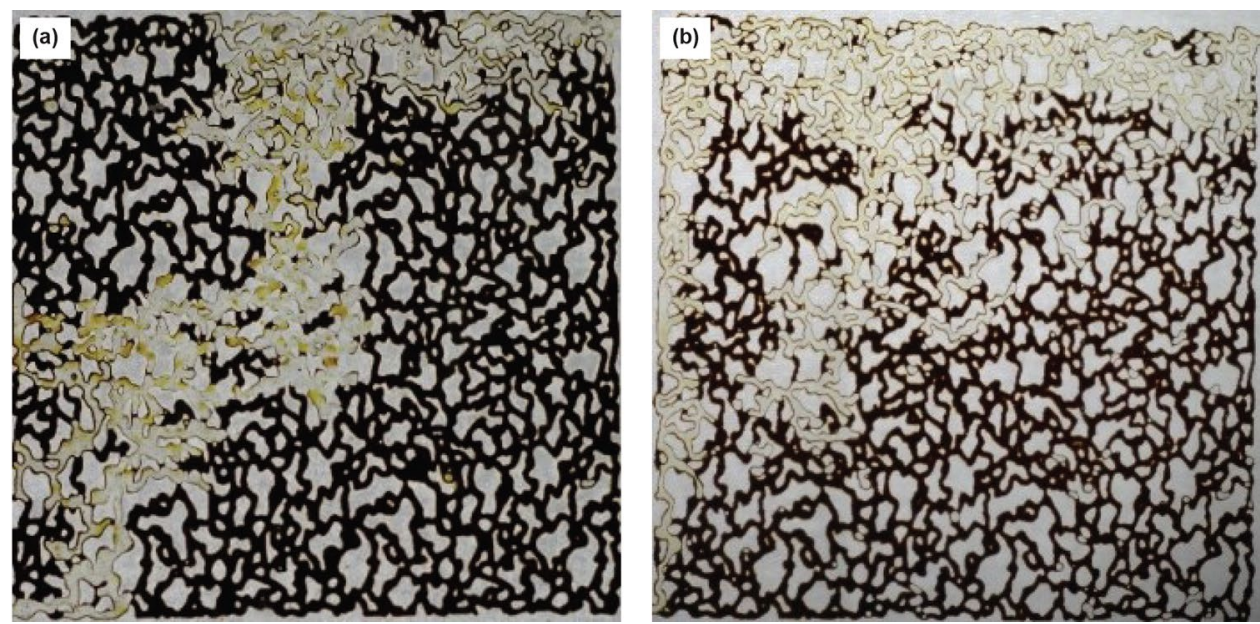

Fig. 10 Oil displacement after the injection of 1 PV of the injected fluid: a PGSW flooding and $\mathbf{b}$ SW0NaCl flooding 
(5) $\mathrm{SW} 0 \mathrm{NaCl}$ and $\mathrm{SW} 3 \mathrm{Na}_{2} \mathrm{SO}_{4}$ solutions, compared to PGSW, raised ultimate oil recovery by $10.12 \%$ and $7.34 \%$, respectively. Therefore, if smart water flooding is to be performed in reservoirs by changing the concentration of salts in the Persian Gulf seawater, the best option will be to eliminate $\mathrm{NaCl}$ or to triple the $\mathrm{Na}_{2} \mathrm{SO}_{4}$ concentration.

Open Access This article is licensed under a Creative Commons Attribution 4.0 International License, which permits use, sharing, adaptation, distribution and reproduction in any medium or format, as long as you give appropriate credit to the original author(s) and the source, provide a link to the Creative Commons licence, and indicate if changes were made. The images or other third party material in this article are included in the article's Creative Commons licence, unless indicated otherwise in a credit line to the material. If material is not included in the article's Creative Commons licence and your intended use is not permitted by statutory regulation or exceeds the permitted use, you will need to obtain permission directly from the copyright holder. To view a copy of this licence, visit http://creativecommons.org/licenses/by/4.0/.

\section{References}

Abbasi P, Abbasi S, Moghadasi J. Experimental investigation of mixedsalt precipitation during smart water injection in carbonate formation. J Mol Liq. 2020;299:112131. https://doi.org/10.1016/j.molli q.2019.112131.

Abubacker J, Al-Attar H, Zekri A, Khalifi M, Louiseh E. Selecting a potential smart water for EOR implementation in Asab oil field. J Petrol Explor Prod Technol. 2017;7:1133-47. https://doi. org/10.1007/s13202-017-0315-5.

Al-Attar HH, Mahmoud MY, Zekri AY, Almehaideb R, Ghannam M. Low-salinity flooding in a selected carbonate reservoir: experimental approach. J Pet Explor Prod Technol. 2013;3:139-49. https://doi.org/10.1007/s13202-013-0052-3.

Al-Hashim H, Kasha AA, Abdallah W, Sauerer B. Impact of modified seawater on zeta potential and morphology of calcite and dolomite aged with stearic acid. Energy Fuels. 2018;32:164456. https://doi.org/10.1021/acs.energyfuels.7b03753.

Alipour Tabrizy V, Hamouda AA, Denoyel R. Influence of magnesium and sulfate ions on wettability alteration of calcite, quartz, and kaolinite: surface energy analysis. Energy Fuels. 2011;25(4):1667-80. https://doi.org/10.1021/ef200039m.

Al-Nofli K, Pourafshary P, Mosavat N, Shafiei A. Effect of initial wettability on performance of smart water flooding in carbonate reservoirs - an experimental investigation with IOR Implications. Energies. 2018;11(6):1394. https://doi.org/10.3390/en110 61394

Alroudhan A, Vinogradov J, Jackson M. Zeta potential of intact natural limestone: impact of potential-determining ions $\mathrm{Ca}^{2+}$, $\mathrm{Mg}^{2+}$ and $\mathrm{SO}_{4}{ }^{2-}$. Colloids Surf A. 2016;493:83-98. https://doi. org/10.1016/j.colsurfa.2015.11.068.

Al-sofi AM, Yousef AA. Insight into smart-water recovery mechanism through detailed history matching of coreflood experiments. In: SPE Reservoir Characterization and Simulation Conference and Exhibition, 16-18 September, Abu Dhabi, UAE, 2013. doi: https ://doi.org/10.2118/166035-MS

Amiri S, Gandomkar A. Influence of electrical surface charges on thermodynamics of wettability during low salinity water flooding on limestone reservoirs. J Mol Liq. 2019;277:132-41. https://doi. org/10.1016/j.molliq.2018.12.069.

Austad T. Water-based EOR in carbonates and sandstones: new chemical understanding of the EOR potential using "Smart Water." Houston: Gulf Professional Publishing; 2013. p. 301-35.

Austad T, Shariatpanahi SF, Strand S, Black CJJ, Webb KJ. Conditions for a low-salinity enhanced oil recovery (EOR) effect in carbonate oil reservoirs. Energy Fuels. 2012;26(1):569-75. https://doi. org/10.1021/ef201435g.

Awolayo A, Sharma H. Impact of multi-ion interactions on oil mobilization by smart waterflooding in carbonate reservoir. J Pet Environ Biotechnol. 2016;7:1-8. https://doi.org/10.4172/2157-7463.10002 78.

Awolayo A, Sarma H, AlSumaiti A. An experimental investigation into the impact of sulfate ions in smart water to improve oil recovery in carbonate reservoirs. Transp Porous Med. 2016;111:649-68. https://doi.org/10.1007/s11242-015-0616-4.

Darvish Sarvestani A, Ayatollahi S, Bahari MM. Smart water flooding performance in carbonate reservoirs: an experimental approach for tertiary oil recovery. J Petrol Explor Prod Technol. 2019;9:264357. https://doi.org/10.1007/s13202-019-0650-9.

Derkani MH, Fletcher AJ, Fedorov M, Abdallah W, Sauerer B, Anderson $\mathrm{J}$, et al. Mechanisms of surface charge modification of carbonates in aqueous electrolyte solutions. Colloids Interfaces. 2019;3(4):62. https://doi.org/10.3390/colloids3040062.

Fathi SJ, Austad T, Strand S. "Smart water" as a wettability modifier in chalk: the effect of salinity and ionic composition. Energy Fuels. 2010;24(4):2514-9. https://doi.org/10.1021/ef901304m.

Fathi S, Austas T, Strand S. Water-based enhanced oil recovery (EOR) by "smart water": optimal ionic composition for EOR in carbonates. Energy Fuels. 2011;25(11):5173-9. https://doi.org/10.1021/ ef201019k.

Fattahi Mehraban M, Ayatollahi S, Sharifi M. Role of divalent ions, temperature, and crude oil during water injection into dolomitic carbonate oil reservoirs. Oil Gas Sci Technol Rev IFP Energ Nouv. 2019;74:1-11. https://doi.org/10.2516/ogst/2019003.

Gandomkar A, Rahimpour MR. The impact of monovalent and divalent ions on wettability alteration in oil/low salinity brine/ limestone systems. J Mol Liq. 2017;248:1003-13. https://doi. org/10.1016/j.molliq.2017.10.095.

Ghalamizade Elyaderani SM, Jafari A, Razavinezhad J. Experimental investigation of mechanisms in functionalized multiwalled carbon nanotube flooding for enhancing the recovery from heavy-oil reservoirs. SPE J. 2019;24(6):2681-94. https://doi. org/10.2118/194499-PA.

Hognesen EJ, Strand S, Austad T. Waterflooding of preferential oil-wet carbonates: oil recovery related to reservoir temperature and brine composition. In: SPE Europec/EAGE Annual Conference, 13-16 June, Madrid, Spain, 2005. doi: https://doi. org/10.2118/94166-MS.

Honarvar B, Rahimi A, Safari M, Khajehahmadi S, Karimi M. Smart water effects on a crude oil-brine-carbonate rock (CBR) system: further suggestions on mechanisms and conditions. J Mol Liq. 2020a;299:112173. https://doi.org/10.1016/j.molliq.2019.11217 3.

Honarvar B, Rahimi A, Safari M, Rezaee S, Karimi M. Favorable attributes of low salinity water aided alkaline on crude oil-brinecarbonate rock system. Colloids Surf A. 2020b;585:124144. https ://doi.org/10.1016/j.colsurfa.2019.124144.

Kakati A, Sangwai JS. Wettability alteration of mineral surface during low-salinity water flooding: role of salt type, pure alkanes, and model oils containing polar components. Energy Fuels. 2018;32(3):3127-37. https://doi.org/10.1021/acs.energyfuel s. $7 \mathrm{~b} 03727$.

Karimi M, Al-Maamari RS, Ayatollahi S, Mehranbod N. Wettability alteration and oil recovery by spontaneous imbibition of low 
salinity brine into carbonates: impact of $\mathrm{Mg}^{2+}, \mathrm{SO}_{4}{ }^{2-}$ and cationic surfactant. J Petrol Sci Eng. 2016;147:560-9. https://doi. org/10.1016/j.petrol.2016.09.015.

Kasha A, Al-Hashim H, Abdallah W, Taherian R, Sauerer B. Effect of $\mathrm{Ca}^{2+}, \mathrm{Mg}^{2+}$ and $\mathrm{SO}_{4}{ }^{2-}$ ions on the zeta potential of calcite and dolomite particles aged with stearic acid. Colloids Surf A. 2015;482:290-9. https://doi.org/10.1016/j.colsurfa.2015.05.043.

Kedar V, Bhagwat SS. Effect of salinity on the IFT between aqueous surfactant solution and crude oil. Pet Sci Technol. 2018;36:83542. https://doi.org/10.1080/10916466.2018.1447953.

Kumar B. Effect of Salinity on the Interfacial Tension of Model and Crude Oil Systems. M.S. Thesis. University of Calgary, 2012. http://dx.doi.org/https://doi.org/10.11575/PRISM/25807.

Lashkarbolooki M, Ayatollahi S. Effects of asphaltene, resin and crude oil type on the interfacial tension of crude oil/brine solution. Fuel. 2018;223:261-7. https://doi.org/10.1016/j.fuel.2018.03.029.

Lashkarbolooki M, Ayatollahi S, Riazi M. The impacts of aqueous ions on interfacial tension and wettability of an asphaltenic-acidic crude oil reservoir during smart water injection. J Chem Eng Data. 2014;59(11):3624-34. https://doi.org/10.1021/je500730e.

Lashkarbolooki M, Ayatollahi S, Riazi M. Mechanistical study of effect of ions in smart water injection into carbonate oil reservoir. Process Saf Environ Prot. 2017;105:361-72. https://doi.org/10.1016/j. psep.2016.11.022.

Mahani H, Keya AL, Berg S, Nasralla R. Electrokinetics of carbonate/brine interface in low-salinity waterflooding: effect of brine salinity, composition, rock type, and $\mathrm{pH}$ on $\zeta$-Potential and a surface-complexation model. SPE J. 2017;22:53-68. https://doi. org/10.2118/181745-PA.

Manshad AK, Olad M, Taghipour SA, Nowrouzi I, Mohammadi AH. Effects of water soluble ions on interfacial tension (IFT) between oil and brine in smart and carbonated smart water injection process in oil reservoirs. J Mol Liq. 2016;223:987-93. https://doi. org/10.1016/j.molliq.2016.08.089.

Manshad AK, Nowrouzi I, Mohammadi AH. Effects of water soluble ions on wettability alteration and contact angle in smart and carbonated smart water injection process in oil reservoirs. J Mol Liq. 2017;244:440-52. https://doi.org/10.1016/j.molliq.2017.09.011.

Meng Z, Yang S, Cui Y, Zhong Z, Liang C, Wang L, Qian K, Ma Q, Wang J. Enhancement of the imbibition recovery by surfactants in tight oil reservoirs. Pet Sci. 2018;15:783-93. https://doi. org/10.1007/s12182-018-0253-y.

Mofrad SK, Saeedi Dehaghani AM. An experimental investigation into enhancing oil recovery using smart water combined with anionic and cationic surfactants in carbonate reservoir. Energy Rep. 2020;6:543-9. https://doi.org/10.1016/j.egyr.2020.02.034.

Mohanty KK, Chandrasekhar S. Wettability alteration with brine composition in high temperature carbonate reservoirs. In: SPE Annual Technical Conference and Exhibition, 30 September-2 October, New Orleans, Louisiana, USA, 2013. doi: https://doi. org/10.2118/166280-MS.

Moosavi SR, Rayhani M, Malayeri MR, Riazi M. Impact of monovalent and divalent cationic and anionic ions on wettability alteration of dolomite rocks. J Mol Liq. 2019;281:9-19. https://doi. org/10.1016/j.molliq.2019.02.078.

Naeli R, Rahimi A, Honarvar B. The effect of seawater on the interfacial tension: smart water flooding. Int J Adv Biotechnol Res. 2016;7:888-96.

Nowrouzi I, Manshad AK, Mohammadi AH. Effects of dissolved binary ionic compounds and different densities of brine on interfacial tension (IFT), wettability alteration, and contact angle in smart water and carbonated smart water injection processes in carbonate oil reservoirs. J Mol Liq. 2018;254:83-92. https://doi. org/10.1016/j.molliq.2017.12.144.

Nowrouzi I, Manshad AK, Mohammadi AH. Effects of dissolved carbon dioxide and ions in water on the dynamic interfacial tension of water and oil in the process of carbonated smart water injection into oil reservoirs. Fuel. 2019;243:569-78. https://doi. org/10.1016/j.fuel.2019.01.069.

Puntervold T, Strand S, Ellouz R, Austad T. Modified seawater as a smart EOR fluid in chalk. J Petrol Sci Eng. 2015;133:440-3. https ://doi.org/10.1016/j.petrol.2015.06.034.

Rahimi A, Honarvar B, Safari M. The role of salinity and aging time on carbonate reservoir in low salinity seawater and smart seawater flooding. J Petrol Sci Eng. 2020;187:106739. https://doi. org/10.1016/j.petrol.2019.106739.

Rashid S, Mousapour MS, Ayatollahi S, Vossoughi M, Beigy AH. Wettability alteration in carbonates during "Smart Waterflood": underlying mechanisms and the effect of individual ions. Colloids Surf A. 2015;487:142-53. https://doi.org/10.1016/j.colsu rfa.2015.09.067.

RezaeiDoust A, Puntervold T, Strand S, Austad T. Smart water as wettability modifier in carbonate and sandstone: a discussion of similarities/differences in the chemical mechanisms. Energy Fuels. 2009;23(9):4479-85. https://doi.org/10.1021/ef900185q.

Rostami P, Mehraban MF, Sharifi M, Dejam M, Ayatollahi S. Effect of water salinity on oil/brine interfacial behaviour during low salinity waterflooding: A mechanistic study. Petroleum. 2019;5(4):36774. https://doi.org/10.1016/j.petlm.2019.03.005.

Saeedi Dehaghani AH, Badizad MH. Impact of ionic composition on modulating wetting preference of calcite surface: implication for chemically tuned water flooding. Colloids Surf, A. 2019;568:470 80. https://doi.org/10.1016/j.colsurfa.2019.02.009.

Saeedi Dehaghani AH, Hosseini M, Tajikmansori A, Moradi H. A mechanistic investigation of the effect of ion-tuned water injection in the presence of cationic surfactant in carbonate rocks: an experimental study. J Mol Liq. 2020;304:112781. https://doi. org/10.1016/j.molliq.2020.112781.

Sheng JJ. Modern chemical enhanced oil recovery: theory and practice. Houstan: Gulf Professional Publishing; 2011.

Sheng JJ. Enhanced oil recovery field case studies. Houstan: Gulf Professional Publishing; 2013.

Shirazi M, Farzaneh J, Kord S, Tamsilian T. Smart water spontaneous imbibition into oil-wet carbonate reservoir cores: symbiotic and individual behavior of potential determining ions. J Mol Liq. 2020;299:112102. https://doi.org/10.1016/j.molliq.2019.112102.

Smallwood PV. Some aspects of the surface chemistry of calcite and aragonite Part I: an electrokinetic study. Colloid Polym Sci. 1977;255:881-6. https://doi.org/10.1007/BF01617095.

Strand S, Hognesen EJ, Austad T. Wettability alteration of carbonates: effects of potential determining ions $\left(\mathrm{Ca}^{2+}\right.$ and $\left.\mathrm{SO}_{4}{ }^{2-}\right)$ and temperature. Colloids Surf A. 2006;275:1-10. https://doi.org/10.1016/j. colsurfa.2005.10.061.

Zaheri SH, Khalili H, Sharifi M. Experimental investigation of water composition and salinity effect on the oil recovery in carbonate reservoirs. Oil Gas Sci Technol Rev IFP Energ Nouv. 2020;75:114. https://doi.org/10.2516/ogst/2020010.

Zhang PM, Austad T. Wettability and oil recovery from carbonates: effects of temperature and potential determining ions. Colloids Surf A. 2006;279:179-87. https://doi.org/10.1016/j.colsu rfa.2006.01.009. 